\title{
Bond Strength of Glued-in Rods in Malaysian Tropical Timber as Influenced by Adhesive, Diameter and Glueline Thickness
}

\author{
N. E. L. ZA'BA*, Z. AHMAD AND A. IBRAHIM \\ Institute of Infrastructure Engineering and Sustainable Management, \\ Universiti Teknologi Mara, 40450 Shah Alam, Selangor, Malaysia
}

\begin{abstract}
Failure in wood structure is mainly caused by improper connection design, construction (fabrication) details, or serviceability. Besides using traditional bolting methods such as nails, screws and bolts to join members, timber members also can be connected by using bonded-in joints. However, current knowledge in the use of this type of timber connection is still limited. This study investigated the performance of bonded-in pultruded rods in timber as connections by exploring the effect of a few parameters such as rod type, diameter of the rod, adhesive type and thickness of the glueline. Pull-out tests were used to characterize the strength of the bonded-in connections. From the results of this study, it was found that strength increased as glueline thickness increased, while strength decreased as the diameter of the rod increased.
\end{abstract}

Key words: Adhesive; bonded-in connection; pultruded rod; pull-out strength; timber; strength; glueline thickness

Bonded-in rods are used to connect timber members, and they have been shown to be more effective than using traditional bolting methods such as nails and screws (Joseph 1999). This type of connection has been used in timber construction for over 30 years in Europe and North America for joining and anchoring glulam members, for rock anchors, for holding down bolts in concrete (Lee et al. 1981), and as rods to secure wooden turbine blades (Riberholt \& Spoer 1983). Bonded-in rods are also used in timber building repairs, and to strengthen the timber (Mettem \& Davis 1996). The connection is made by using high strength resins to produce a concealed timber connection. Bonded-in joints using rods are known to offer improvements by reducing weight and end-splitting, eliminating very stiff connections when loaded in an axial direction, providing greater fire resistance, and also producing a neater appearance. A good compilation of existing knowledge, including lists of basic literature, can be found in the Proceedings, PRO 22 of the 2001 RILEM Symposium on "Joints in Timber Structures", and in the Proceedings of the CIB W18Meetings No. 28, 32, 33 and 34.

Steel rods bonded into timber elements are very efficient in introducing high forces into the timber structural members as well as in strengthening timber which is perpendicular to the grain. Bonded-in steel rods in wooden members have been investigated by numerous researchers. Most of these studies used softwood. However, there is no published work on bonded-in rods in Malaysian tropical timber. Hence, there is a need to investigate the performance of bonded-in connections using Malaysian tropical timber.

* Corresponding author (e-mail: lydia85@live.com) 
Molina et al. (2009) conducted static and cyclic tests to determine the fatigue of steel rods connections, using two species of reforested wood, three types of commercial adhesives and at three levels of wood moisture content. The studies revealed that fatigue failure may occur in any of the materials used for the connection, i.e. steel rod, adhesive or timber species. Other than that, the fatigue behavior exhibited a visible impact, damaging mainly the steel rods and representing a potential fatigue risk for bonded-in rods used to form the connection in log-concrete composite bridge decks (Molina et al. 2009). The effect of spacing between the steel rods and the distance to the timber edge were tested parallel and perpendicular to the grain-by Blass and Laskewitz (1999), and it was concluded that the pull-out strength of rods with the same diameter and anchoring length set perpendicular to the grain was $20 \%-50 \%$ higher than for rods bonded in parallel to the grain. According to Widmann et al. (2006), the pullout strength is influenced by the wood density. There are also a few studies comparing the performance of threaded rods and smooth rods on the mechanical bond between the bolt and the resin. Johansson (1995) claimed that there is an advantage of threaded bolts over smooth steel rods because the latter are not effective as it is difficult to achieve sufficient adhesion between a smooth surface and the resin. Other than that, Hamad (1995) and Harvey (2003) investigated the optimization of the rib geometry of steel reinforcing bars to enable the use of shorter bonded-in lengths for a given load. Beside using steel as a general material in bonded-in joints, fibre-reinforced plastic can be used to improve resistance to corrosion which is useful in a humid or acid environment, to lower the weight of the connection, to provide easier and faster handling and installation, as well as to be more compatible with the resin and timber due to more compatible material properties. Harvey and Ansell (2000) investigated the effect of moisture content, wood type, surface preparation, type of adhesive, and glueline thickness when using glass fibre-reinforced plastic (GFRP). Figure 1 shows the possible failure modes observed by Harvey and Ansell (2000). Number 1 is failure in the rod/adhesive interface, number 2 indicates failure in the adhesive/timber interface, number 3 shows failure in the timber close to the adhesive/ timber interface, number 4 illustrates failure in the timber away from the adhesive/timber interface, while number 5 is failure in the timber also along the block.

Even with these parameters studied, the results are still considered insufficient to establish standards for the use of GFRP. Although there are standards such as Eurocode 5 which provides recommendations for bonded-in connections, the information is very limited as it does not consider the thickness of gluelines.

Several design approaches and code models have been published. By comparing these models and approaches, some discrepancy and even partial contradictions between the models, especially regarding the treatment of isolated parameters, can be found. With

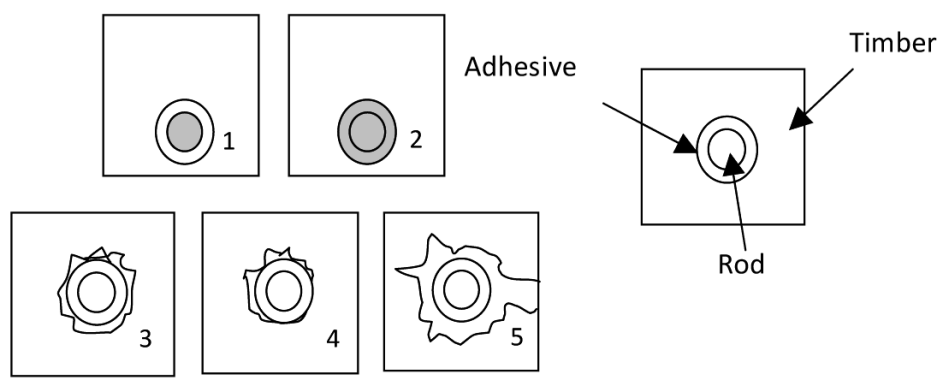

Figure 1. Possible pull-out failure modes. 
this background, a small test programme was initiated to study the influence of a selection of these parameters, known or supposed to determine the pull-out strength of single, axially loaded pultruded glass fibre-reinforced plastic (GFRP) rods bonded with two types of commercial epoxy-based adhesives in timber from Kempas wood species. The tests were focussed on determining the influence of rod diameter, $\phi_{\text {rod }}$, (or the corresponding drill-hole, $\left.\phi_{\text {hole }}\right)$ and glueline thickness, $h$, on the pull-out strength of the glued-in rods.

Important objectives of the test programme were that it should be based on practical situations and dimensions, and that it should enable a comparison to be made with similar test series. These objectives could only be achieved by permitting certain compromises regarding the test layout. For example, although in practice the use of one single rod will not or hardly ever be the normal case, all tests described here were carried out on connections with a single rod. This is because the examination of such a connection provided a good basis to study the influence of isolated parameters. Moreover, it was possible to quantify the influence of the parameters selected for the present study on the pull-out strength of the axially loaded rods, and to propose an adequate design model.

\section{MATERIALS AND TEST METHODS}

\section{Materials}

The selected timber used in this study was from a medium hardwood species, namely, Kempas (Koompassia malaccensis), from strength group 2 with a density of $900 \mathrm{~kg} / \mathrm{m}^{3}$. This species was chosen because it is commonly used for roof trusses, and is easily available.

Glass fibre-reinforced plastic (GFRP) rods with diameters 8 and $12 \mathrm{~mm}$ were used with a modulus of elasticity of $150000 \mathrm{~N} / \mathrm{mm}^{2}$. GFRP rods were sandpapered using coarse sand paper, and degreased with ethanol to aid bonding with the adhesive.
The adhesives used in this study were Sikadur ${ }^{\circledR-30}$ and Morstrong. Sikadur ${ }^{\circledR-30}$ was supplied by Sika Sdn. Bhd, Malaysia. It is a gap-filling, thixotropic and structural two-part adhesive, based on a combination of epoxy resins and a special filler, designed for use at normal temperatures between $+8^{\circ} \mathrm{C}$ and $+35^{\circ} \mathrm{C}$. Morstrong, which is also a gap-filling adhesive was supplied by Morstrong Industries Sdn. Bhd.

\section{Specimen Preparation and Test Methods}

Timber specimens for the pull-out tests were prepared using timber blocks of size $100 \mathrm{~mm} \times$ $100 \mathrm{~mm} \times 60 \mathrm{~mm}$ by ensuring that the grain was parallel. A hole was drilled parallel to the grain with the diameter of the drilled hole being larger than the rod diameter to allow for the required glueline thickness. The specimens were left in a temperature controlled room at $28^{\circ} \mathrm{C}$ to avoid shrinkage prior to inserting the adhesives and rods. A gun was used for injecting the adhesive into the hole. The rod was slowly pushed in and gently rotated to squeeze out the excess adhesive without causing any air voids. An O-ring was inserted into the hole to centre the position of the rod. All the specimens were left for 10 days at room temperature for curing. Ten replicates were prepared for each treatment.

A $250-\mathrm{kN}$ capacity universal testing machine (UTM) was used to conduct the pull-out tests. Axial loads were applied with a crosshead of $2 \mathrm{~mm} / \mathrm{min}$. To support and align the specimen in the pull-out test, a special jig made from stainless steel as shown in Figure 2(b) was used for the specimen to be gripped by the machine as shown in Figure 2.

Observations were made on the failure modes of the specimens to better understand the behavior of the bonded-in timber. Average shear strength, $\tau$, at the adhesive, timber and rod interfaces was calculated by dividing the failure load by the bond area as shown in Figure 3, using Equations 1 and 2. 


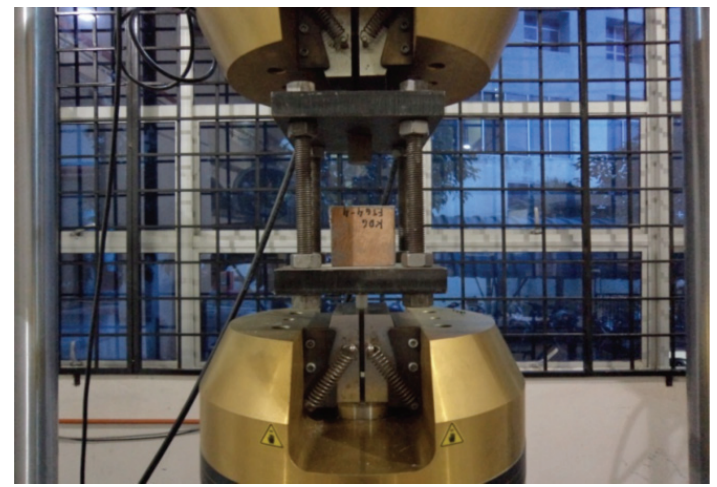

(a)

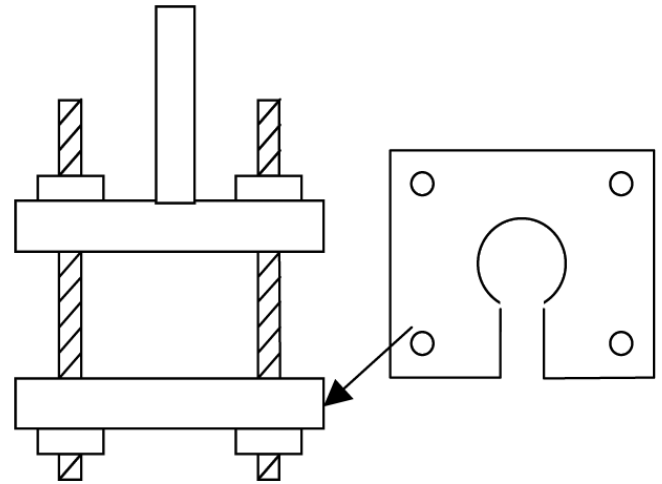

(b)

Figure 2. Experimental set-up for a pull-out test: (a) pull-out specimen attached to UTM, (b) schematic diagram of the cage (jig) to hold the pull-out specimen.

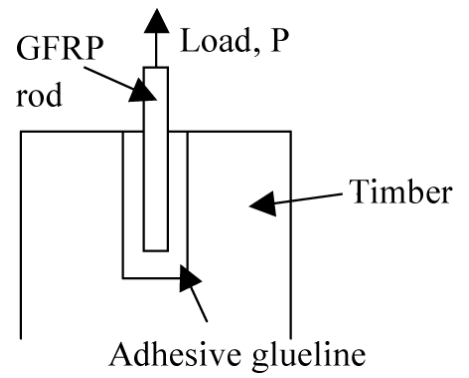

Figure 3. Schematic diagram of bonded-in rod in timber.

Adhesive-timber interface:

$$
\tau_{\mathrm{ta}}=\frac{P_{\max }}{\pi \phi_{\text {hole }} L}
$$

Rod-adhesive interface:

$$
\tau_{\mathrm{ra}}=\frac{P_{\max }}{\pi \phi_{\mathrm{rod}} L}
$$

where, $\phi_{\text {hole }}$ and $\phi_{\text {rod }}$ are the diameters of the drilled hole and rod, respectively, and $L$ is the rod embedment length which was $50 \mathrm{~mm}$ in all cases. Due to the different diameters, the bond area at the adhesive/timber interface was bigger than the bond area at the adhesive/rod interface which resulted in different strength values.

\section{RESULTS AND DISCUSSION}

\section{Influence of Adhesive Type on the Pull-out Strength}

When constructing the bonded-in connection, the strength of the joint will depend in the type of adhesive used. Table 1 shows a summary of the pull-out strength for all the parameters studied. It can be seen that the bonded-in joints were affected by the various parameters, and that the influence was clearly visible with the 8 -mm rods but not as markedly as when using 12 -mm rods.

For the bonded-in joints using Sikadur with 8 -mm rods, the pull-out strength increased as the glueline thickness increased. However, there was no significant difference in the pull-out strength when using Morstrong adhesive with 8 -mm rods for the bonded-in joints. Comparing both the adhesives, the pull-out strength of the bonded-in joints using Sikadur was 26\% higher than when using Monstrong adhesive. With Sikadur adhesive, $50 \%$ of the specimens failed at the rod/adhesive/timber interface, while Morstrong adhesive tended to fail at the rod/ adhesive interface (see Figure 3).

The FE-modelling performed by Serrano and Gustafsson (1999) on bonded-in rods using 


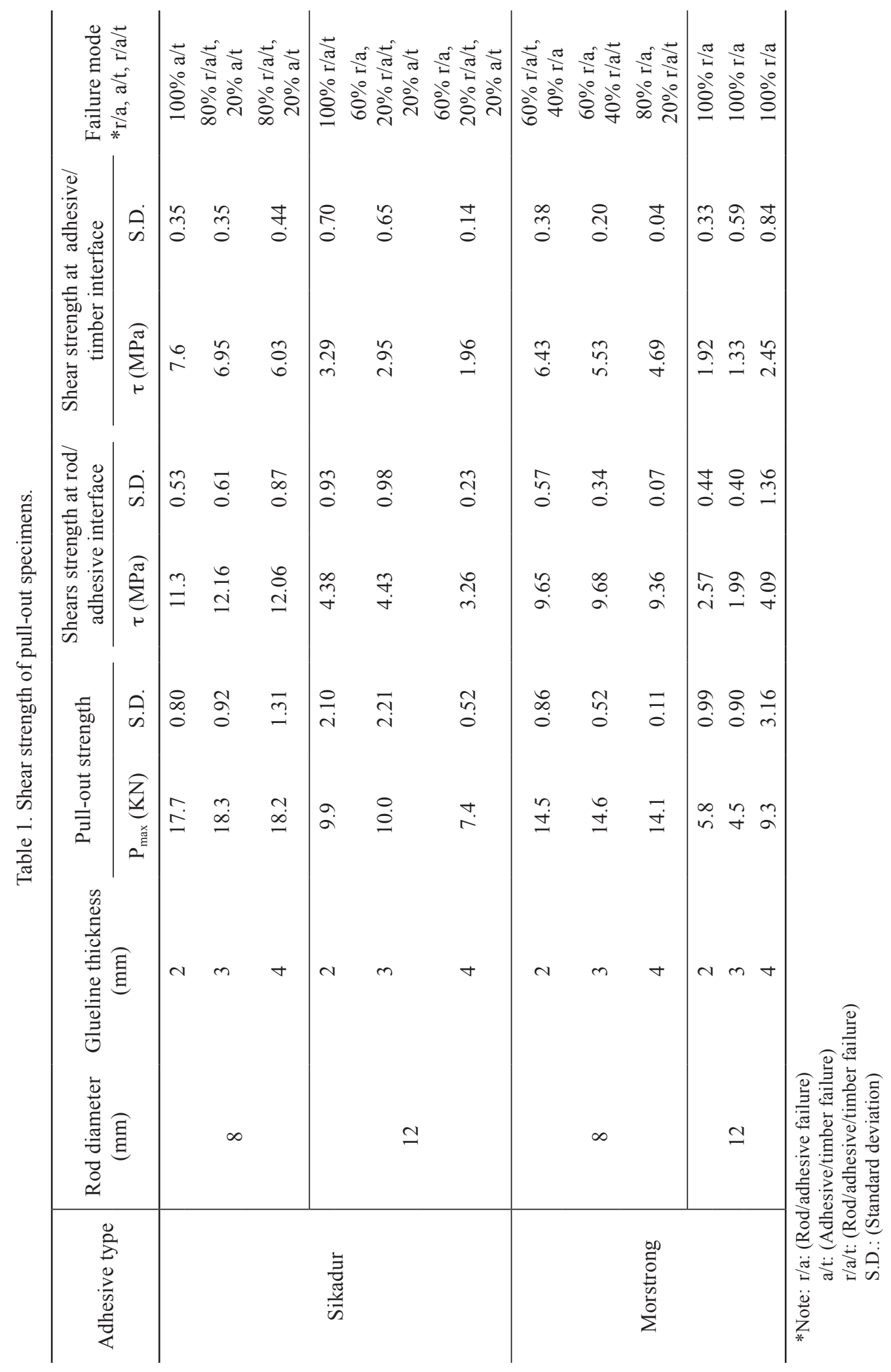




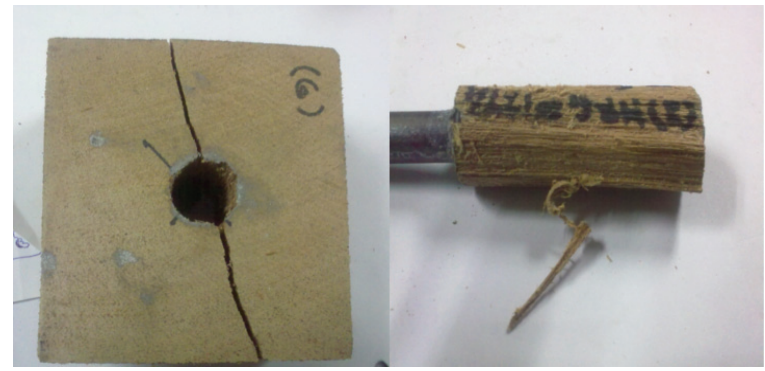

(a)

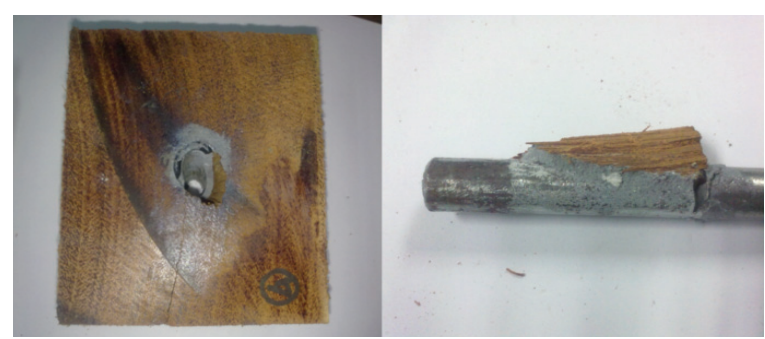

(b)
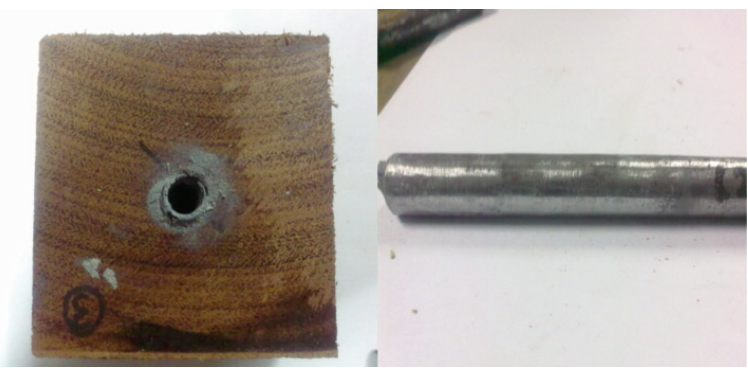

(c)

Figure 3. Bonded-in rods with different modes of failure: (a) failed in timber, (b) failed in rod/adhesive/timber interface and (c) failed in rod/adhesive interface.

ductile and brittle adhesives showed that the shear strength increased with the use of ductile adhesives with high fracture energy. Therefore, in this case, the increase in shear strength of the bonded-in rods using Sikadur as compared with Monstrong may be due to the higher fracture energy of Sikadur as this adhesive is epoxy-based with the addition of a special filler to improve toughness. An improvement in adhesive bond strength has been reported by many researchers using CTBN liquid rubber as a modifier (Bascom \& Cottington 1976; Hunston et al. 1984; Huang \& Kinloch 1993). Achary et al. (1991) reported a three-fold increase in lap shear strength using carboxyl terminated poly (propylene glycol) adipate as liquid rubber. Ratna and Banthia (2000) reported a two-fold increase in lap shear strength using carboxyl-terminated poly (2-ethylhexyl acrylate) (CTPEHA) as liquid rubber.

\section{Influence of Glueline Thickness and Rod Diameter}

As the tests follow a certain range of geometrical proportions in terms of rod diameter $\phi$ and glueline thickness $h$, the nominal shear strength $f v$ is calculated assuming a constant distribution of the shear stresses over the bonded area. 
Besides analysing the test results with regard to the relationship between $\phi$ and $h$, the influences of the single parameters and $\phi$ were studied to get an idea of their power of their influence. Regarding the influence of the glueline thickness on the pull-out strength of the rods, the relationship can be approached based on $h^{0.05}$ suggesting a relationship existed between pull-out strength and thickness of the glueline. When combining the effect of the various glueline thicknesses and diameters of the rod, the nominal shear strength of bondedin rod can be estimated based on the following equation:

$$
f_{v}=k_{0} h^{0.05} \phi^{1 / 3}
$$

Validation of Equation 3 is not shown here. Figure 2 shows the fitting of the model to the relationship between the pull out strength and glueline thickness at various diameters of the rod.

As the gluelines thickness increased, the failure modes changed to the rod/adhesive/ timber interface from the rod/adhesive or adhesive/timber interface. In some cases, $10 \%$ of the timber blocks cracked and were completely split. As the shear stress decreased, the failure was mainly in the rod/adhesive interface. The effect of rod diameter on average peak interfacial shear stress was reflected by a decrease in shear strength of the adhesive/ timber interface as rod diameter increased. The failure mode for the $8-\mathrm{mm}$ rod diameter was close to the adhesive/timber interface while for the $12-\mathrm{mm}$ rod diameter failure was in the rod/ adhesive interface.

\section{CONCLUSION}

Pull-out tests were conducted on Kempas species with $8-\mathrm{mm}$ and 12-mm diameter steel rods bonded with two types of adhesives, which were Sikadur and Morstrong. The investigation examined the influence of rod diameter and glueline thickness on the pull-out strength. The results from the experiment reveal that:

- As glueline thickness increased, the pull-out strength also increased, on condition that there was a good bond between the rod and the adhesive.

- As rod diameter increased, the shear strength of the adhesive/timber interface decreased.

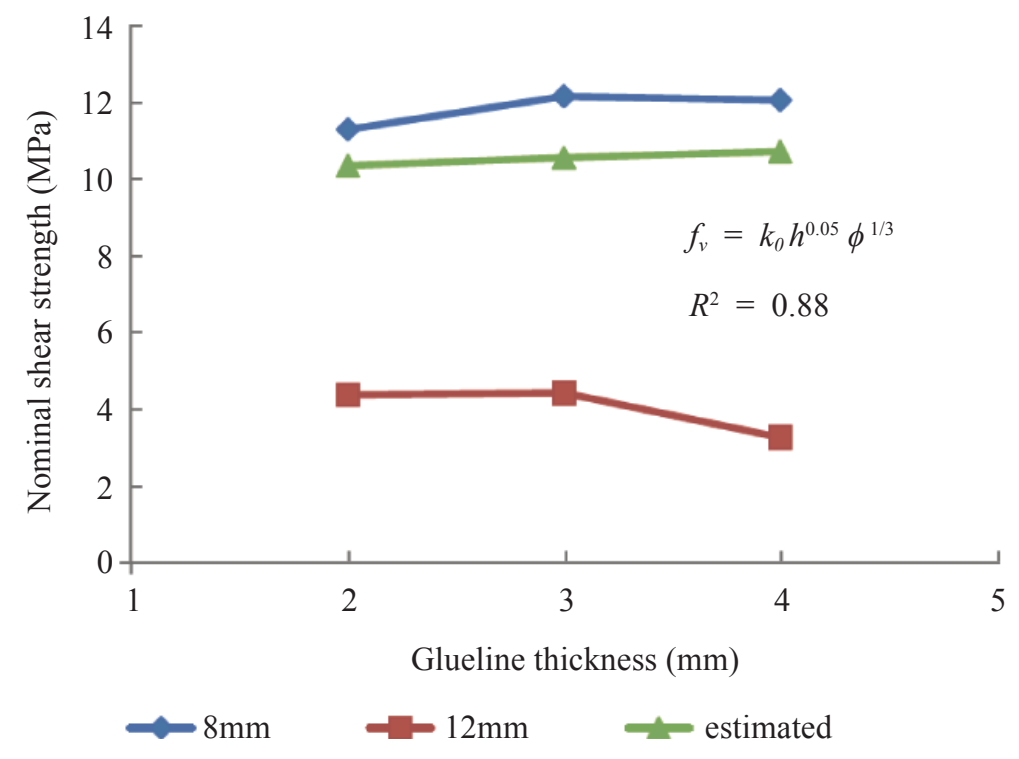

Figure 2. Design model to calculate the nominal shear strength of single, axially loaded rods in bonded-in timber connections. 
- Pull-out strength using Sikadur was $26 \%$ higher than when using Morstrong adhesive, and tended to fail at the rod/ adhesive/timber interface.

\section{Date of subwmission: May 2012}

Date of acceptance: June 2012

\section{REFERENCES}

Achary, PS, Gouri, C \& Ramamurty, R 1991, 'Carboxyl-terminated poly(propylene glycol) adipate-modified room temperature curing epoxy adhesive for elevated temperature service environment', Journal Applied Polymer Science, vol. 42 , pp. $743-752$.

Bascom, WD, Cottington, RL, Jones, RL \& Peyser, P 1975, 'The fracture of epoxy- and elastomer-modified epoxy polymers in bulk and as adhesives', Journal Applied Polymer Science, vol. 19 , no. 9, pp. $2545-2562$.

Blass, HJ \& Laskewitz, B 1999, 'Effect of spacing and edge distance on the axial strength of glued-in rods', in Proceeding CIB-W18A, Graz, Austria.

Hamad, BS 1995, 'Bond strength improvement of reinforcing bars with specially designed rib geometries', ACI Structural Journal (American Concrete Institute), vol. 92, no. 1, pp. 3 - 13.

Harvey, K \& Ansell, MP 2000, 'Improved timber connections using bonded-in GFRP rods', in Proceedings of 6th World Conference on Timber Engineering, Whitsler, British Columbia, 31st July to 3rd August 2000, Paper P04.

Harvey, K 2003, 'Improve timber connections using bonded-in GFRP rods', $P h D$ thesis, University of Bath, UK.

Huang, Y, Hunston, DL, Kinloch, AJ \& Riew, CK 1993, 'Toughened plastics I', in Advances in chemistry series, 233, eds CK Riew \& AJ Kinloch, American Chemical Society, Washington DC.
Hunston, DL, Kinloch, AJ, Shaw, SJ \& Wang, SS 1984, 'Characterization of the fracture behavior of adhesive joints', in Adhesive Joints, ed KL Mittal, Plenum Press, New York.

Johansson, CJ 1995, 'Glued-in bolts', in Structural timber education programme lecture, Part 1, Lecture C14. 1st edn, ed HJ Blass, Centrum Hout, Almere, Netherlands, C14/1-C14/7.

Joseph, DR 1999, 'Flitched beams for use in domestic flooring', Final Year Research Project, Faculty of the Built Environment, University of the West of England, UK.

Lee, NK, Mayfield, B \& Snell, C 1981, 'Detecting the progress of internal cracks in concrete by using embedded graphite rods', Magazine of Concrete Research, vol. 116, pp. $180-183$.

Mettem, CJ, \& Davis, G 1996, 'Resin bonded repair systems for structural timber', Construction repair, March/April, pp. 23 - 28.

Molina, JC, Calil, CJ \& Carreira, MR 2009, 'Pullout strength of axially loaded steel rods bonded in glulam at a $45^{\circ}$ angle to the grain', in Laboratory of wood and timber structures, Carlos School of Engineering, University of Sao Paulo.

Ratna, D \& Banthia, AK 2000, 'Toughened epoxy adhesive modified with acrylate based liquid rubber', Polymer International, vol. 49, no. 3, pp. $281-287$.

Riberholt, H \& Spoer, D 1983 'Design of the inglues rods that are used for the wingblade root section on Nibemolle-B', Series R-Denmarks Tekniske Hojskole, Afdelingen for Baerende Konstructioner, no. 167.

Serrano, E \& Gustafsson, PJ 1999, 'Influence of bondline brittleness and defects on the strength of timber finger-joints', International Journal of Adhesion and Adhesives, vol. 19, no. 1, pp. 9-17.

Widmann, R, Steiger, R \& Gehri E 2006, 'Pull-out strength of axially loaded steel rods bonded in glulam perpendicular to the grain', Material and Structures, vol. 40 , no. 8 , pp. $827-838$. 